\begin{tabular}{|l|l|}
\hline Postprint Version & 1.0 \\
\hline Journal website & $\underline{\text { http://www.tandfonline.com/doi/abs/10.1080/19317611.2011.620686 }}$ \\
\hline Pubmed link & $10.1080 / 19317611.2011 .620686$ \\
\hline DOI &
\end{tabular}

This is a NIVEL certified Post Print, more info at http://www.nivel.eu

\title{
The Incidence of Sexual Dysfunction in Patients Attending Dutch General Practitioners
}

\author{
HARALD KEDDE ${ }^{\mathrm{A}}$, GÉ DONKER ${ }^{\mathrm{B}}$, PETER LEUSINK ${ }^{\mathrm{C}} \&$ HANS KRUIJER $^{\mathrm{A}}$ \\ ${ }^{a}$ Rutgers WPF, Utrecht, The Netherlands \\ ${ }^{\mathrm{b}}$ NIVEL, Netherlands Institute for Health Services Research, Utrecht, The Netherlands \\ ${ }^{\mathrm{c}}$ University Medical Center Utrecht, Utrecht, The Netherlands
}

\begin{abstract}
Data on patients with a sexual dysfunction were collected in 45 Dutch general practices between 2003 and 2008. The aim of the study was to determine the incidence of patients with a sexual dysfunction, associated health problems, and related interventions performed by their general practitioners (GPs). The study design was a dynamic cohort study comparing 6 years of data on patients with a sexual dysfunction. Participating GPs were asked to record weekly all consulting patients who presented with a sexual dysfunction. In an additional questionnaire, these problems and associated interventions were specified. Incidence of sexual dysfunctions varied between 132 per 100,000 per year for male patients and 60 per 100,000 per year for female patients. Men mainly consulted a GP for erectile dysfunction, and women mainly consulted a GP for hypoactive sexual desire disorder and dyspareunia. Sexual desire problems were more often associated with comorbid problems such as psychological and relationship problems and medication use than other sexual dysfunctions. Female patients showed more cooccurrence of sexual dysfunction and were more often referred to secondary care services than were male patients. During the period of 2003 to 2008, the help-seeking pattern of men and women consulting their GP for a sexual dysfunction appears to be stable. The presence of comorbid problems indicates that GPs are often dealing with complex multifactorial dynamics. Co-occurrence of sexual dysfunction among women probably resulted in a higher referral rate to secondary care services. Therefore, a gender-sensitive approach and an open mind to differences in sexual identity are needed for counseling in and treatment of sexual dysfunction.
\end{abstract}

\section{INTRODUCTION}

Researchers have examined the prevalence of sexual dysfunction for several decades. Most available studies indicate that sexual dysfunction is highly prevalent among the population (see Lewis et al., 2010 Simons \& Carey, for an overview). In their literature review, Lewis et al. found that about $40 \%$ to $45 \%$ of adult women and $20 \%$ to $30 \%$ of adult men have at least one manifest sexual dysfunction, if the occurrence of the dysfunction (rather often, often, nearly always, and always) is taken into account. There is great variability in reported prevalence rates of particular sexual dysfunctions due to differences in definition of sexual dysfunction, degree of severity, difference in age groups, and length of time the dysfunction was present. In summary, prevalence rates among women for low levels of sexual desire varied from $17 \%$ to $55 \%$; arousal and lubrication problems varied from $8 \%$ to $28 \%$; manifest orgasmic dysfunction varied from 
$16 \%$ to $25 \%$; and dyspareunia varied from $14 \%$ to $27 \%$. Erectile dysfunction is the major sexual dysfunction in men and is mainly present among older men: 40 to 59 years old, $2 \%$ to $35 \%$; 60 to 80 years old, $20 \%$ to $100 \%$. Sexual desire or interest reported for 40 - to 80 -year-olds were $8 \%$ to $18 \%$; ejaculatory disturbances were reported among $8 \%$ to $30 \%$; and orgasm problems ranged from $12 \%$ to $19 \%$. Simons and Carey reviewed studies performed prior to the turn of the century and found a $0 \%$ to $5 \%$ community prevalence for erectile disorder and $0 \%$ to $3 \%$ prevalence for male hypoactive sexual desire disorder. Oneyear figures provided a community prevalence estimate of $7 \%$ to $10 \%$ for female orgasmic disorder and $4 \%$ to $5 \%$ for premature ejaculation. A nationally representative study recently conducted in The Netherlands indicated that the prevalence of sexual dysfunction (when both occurrence [often, very often, always] and personal distress are taken into account) is currently $20 \%$ in women and $17 \%$ in men (Kedde \& De Haas, 2006). These figures clearly indicate that sexual function problems are an important public health concern.

Considering these prevalence rates, the question arises as to how many people consult — as their first point of contact - a general practitioner (GP) concerning a sexual dysfunction. Furthermore, there is no insight into possible changes in incidence rates over time. Available research on this subject is scarce, often limited, and outdated (Courtney, 1976; Golombok, Rust, \& Pickard, 1984; Read, King, \& Watson, 1997: Spence, 1992). There is only one recent study, which indicated that $3 \%$ to $4 \%$ of people registered with a general practice had an entry of sexual function problems in their practice records (Nazareth, Boynton, \& King, 2003). However, none of these studies consider the role of GPs in terms of management and interventions. One would expect a GP, who has information about the lifetime development of a person's health and welfare and who is aware of the biopsychosocial context of a person's life, to be the first professional to counsel the patient on sexual concerns or problems. Nevertheless, some studies point to the contrary. In 2001, Dutch GPs were asked if they considered counseling on sexual problems to be their responsibility. Only about 40\% answered in the affirmative, a significant decline compared with 1987, when more than $60 \%$ answered in the affirmative (Kolthof, 2004). Another study showed that patients themselves were also reluctant to discuss sexual problems, although perceptions of the response individuals would receive from their GP affected their decision to seek help (Marwick, 1999). One qualitative study suggested six factors that could influence the decision of individuals and couples to seek help from primary health care professionals for sexual and/or relationship difficulties. Only two factors could be identified that were related to the individual; the other four factors were related to the context and relationship the patient was in (Fitter, Hayter, \& Wylie, 2009). While patient and GP wait for each other, all kinds of opportunities arise to discuss sexual problems. Subjects like reproductive health, depression, gynecological and urological symptoms, cardiovascular diseases, neurological problems all have consequences for one's sexual health. Equally important, sexual problems can lead to emotional, psychological, and relationship issues (Whipple, Knowles, \& Davis, 2007). In most cases, the GP can act like he does in other consultations: He asks questions, listens, formulates the need for help, reassures, advises, and gives psychoeducation or medication. Sometimes a referral to a sexologist is needed.

Reliable data on the proportion of patients who consult their GP for the first time concerning a sexual dysfunction - in this study referred to as "incidence"-and related interventions by GPs are critical for prevention and treatment planning but also to improve the training of GPs with regard to sexual health. The aim of the present study, therefore, was to obtain adequate and representative information about: (1) the incidence of patients attending their GPs concerning a sexual dysfunction, including assessing trends in consultation behavior during the years 2003 through 2008, (2) associated health problems, and (3) the quality of care provided by GPs through evaluating the interventions applied.

\section{METHODS}

\section{Procedure}

Data were collected through the Dutch Sentinel General Practice Network 2003-2008 (e.g., Donker, 2009). The Dutch Sentinel General Practice Network is composed of about 45 general practices, nationally representative by age, gender, geographical distribution, and population density. The total number of registered patients within these practices varied from 134,000 to 145,000 patients during 2003 to 2008, and the number of participating practices varied from 39 to 46 . GPs reported the occurrence of a number of illnesses, incidents, and interventions on a weekly basis. From 2003, GPs were asked to keep a weekly record of all patients with one or more sexual dysfunctions in their electronic medical record. In an additional questionnaire, these sexual dysfunctions were specified using the Classification of Sexual 
Problems, which is widely applied in outpatient clinics for sexology in The Netherlands (National Platform for Outpatient Clinics in Sexology, 1998) and contains 17 sexual dysfunctions within four clusters (Table 1). A sexual dysfunction had to be the main reason for the consultation to be included in this study. Because sexual dysfunctions often co-occur, a maximum of 3 other sexual dysfunctions could be listed by the GP in the additional questionnaire.

\section{[TABLE 1]}

Additionally, GPs were asked to record (1) standard demographic data; (2) whether the patient's partner was present during the consultation; (3) the possible association with psychological, relational, and physical problems, the use of medication, and surgery; (4) the number of consultations in which sexual function problem(s) were discussed; (5) the actions and interventions that were undertaken by the GP; (6) whether a follow-up consultation was scheduled; and (7) whether the GP had referred the patient to a specialist, and if so, to what discipline.

\section{Statistics}

The incidence of patients consulting a GP about sexual dysfunction was determined by calculating the number of first-time consultations per 100,000 registered patients. To assess differences in incidence rates during 2003 to 2008, 1-year total incidence rates of sexual function problems were calculated for every practice separately. Subsequently, analysis of variance (ANOVA) tests - including post-hoc Bonferroniwere carried out to determine whether incidence rates varied between years. To calculate the association of sexual dysfunction and comorbidity, sexual dysfunction problems were recoded into four clusters: sexual desire problems, sexual arousal problems, orgasm problems, and sexual pain problems. The clusters and associated sexual dysfunction problems are presented in Table 1 . Subsequently, $\chi^{2}$ analyses were carried out to determine whether comorbidity items were significantly associated with, for example, sexual desire problems in comparison with the other three remaining clusters of sexual problems. To find possible differences in GP interventions by patient gender and whether GPs scheduled follow-up consultations or referrals for a specific cluster of sexual problems, $\chi^{2}$ analyses were carried out to determine differences by gender and in follow-up and referrals between clusters of sexual problems.

\section{RESULTS}

\section{Demographic Characteristics}

Overall, 726 patients consulted a GP for the first time concerning a sexual dysfunction during the period from 2003 to 2008. Approximately $95 \%$ of the patients consulting their GP for sexual dysfunction had steady partners, but in most cases, patients consulted their GP without their partner (92\%). Men consulted a GP twice as often as women (men, $\mathrm{n}=492$; women, $\mathrm{n}=234$ ). Men were significantly older than women, $\mathrm{F}(1)=179.67, \mathrm{P}=.00$. The majority of the male patients were between 40 and 80 years of age $(70 \%)$, with a mean age of 54.9 years $(\mathrm{SD}=14.1)$. The majority of female patients were between 20 and 60 years of age $(68 \%)$, with a mean age of 38.3 years $(\mathrm{SD}=14.3)$. Most patients were native Dutch $(79 \%)$, a small proportion was nonnative (12\%), and the ethnic background was unknown for $9 \%$ of patients.

\section{Incidence of Sexual Dysfunction}

During the period from 2003 to 2008, the overall incidence of men consulting a GP for sexual dysfunctions was 132 per 100,000 (Table 2). For women, the incidence was 60 per 100,000. In total, 95 per 100,000 consulted their GP for sexual function problems. In men, erection problems were registered most frequently by far, followed by subjective arousal problems and premature orgasms. In female patients, dyspareunia and hypoactive sexual desire were reported most frequently. ANOVA tests indicated no significant differences in incidence rates of sexual dysfunctions between each year of data collection, $\mathrm{F}(5,169)=1.55, \mathrm{p}=.22$. GPs reported significantly more co-occurrences of sexual dysfunction among women in comparison with men $\left(27 \%\right.$ vs. $\left.12 \% ; \chi^{2}(1)=23.62, p=.00, \varnothing=.18\right)$. 


\section{[TABLE 2]}

\section{Sexual Dysfunction and Associated Health Problems}

Sexual desire problems in men were more often associated with psychological problems and relationship problems than were sexual arousal problems, orgasm problems, and sexual pain problems as reported by GPs (Table 3). In women, sexual desire problems were related to psychological problems and to medication use and were less often related to physical problems. Sexual arousal problems in women were also associated more with medication use. Sexual pain problems were more frequently related to physical problems and less often to psychological problems and medication use.

\section{[TABLE 3]}

\section{Interventions Performed by GPs}

Approximately 8 out of 10 GPs performed a sexological history, $50 \%$ of the patients received information or advice, and medication was prescribed for $40 \%$ of patients (Table 4$)$. Women were more frequently physically examined than were men, $\chi^{2}(1)=71.05, p=.00, \varnothing=.32$. Prescription of drugs, $\chi^{2}(1)=66.29, p$ $=.00, \varnothing=.29$, and laboratory examination requests, $\chi^{2}(1)=8.52, p<.01, \varnothing=.11$, were more often performed with regard to male patients. More than half of the patients received a follow-up consultation, and $13 \%$ were referred by their GP after one consultation. Approximately one third of patients was neither referred nor received a follow-up consultation. Female patients were more often referred after one consultation than were male patients, $\chi^{2}(1)=39.65, p=.00, \varnothing=.24$. Male patients more often than female patients received only one consultation, without follow-up or referral, $\chi^{2}(1)=16.34, p=.00, \varnothing=.15$. In cases where patients were referred after one consultation, female patients were more often referred to secondary care services than were male patients, $\chi^{2}(1)=5.04, \mathrm{p}<.05, \emptyset=.25$.

\section{[TABLE 4]}

To explore whether GPs arranged follow-up consultations or referrals for a specific cluster of sexual problems, $\chi^{2}$ tests were carried out to determine differences between these clusters. Outcomes of follow-up consultations did not reveal any differences; GPs were not more likely to arrange follow-up consultations for a specific type of sexual problem. Looking at the referral rates, men with sexual arousal problems were less often referred after one consultation in comparison with the three other clusters of sexual problems, $\chi$ ${ }^{2}(1)=29.63, p=.00, \varnothing=-.25$. Differences in referrals between sexual problems among female patients were not found.

\section{DISCUSSION}

During the period from 2003 to 2008, the help-seeking pattern of men and women consulting their GP for a sexual dysfunction appears to be stable. Women most often consulted a GP for hypoactive sexual desire disorder and dyspareunia. Men consulted a GP about a sexual dysfunction twice as often compared with women, and in most cases for erectile dysfunction, which is more common among older men (Lewis et al., 2010). Therefore, in this study, men were on average significantly older than women. It is very likely that the difference in treatment possibilities for men and women is leading to more men seeking help, considering the relatively large number of pharmacological opportunities for men with erectile dysfunction compared with the few opportunities for women.

Erectile dysfunction in men and hypoactive sexual desire disorder and dyspareunia in women are also the sexual dysfunctions reported most frequently in sexological outpatient clinics - which is a secondary care setting in the Netherlands (Kruijer \& Kedde, 2010). Notably, women visited sexological outpatient clinics more frequently than did men (Kruijer \& Kedde). This opposite proportion of male-female patients within sexological outpatient clinics is reflected in the referral rate by GPs in this study: GPs diagnosed significantly more comorbid dysfunction in female patients, which indicates that their sexual problems are more complex than those of men. This difference therefore resulted in a higher referral rate to secondary care services after one consultation.

In our study, sexual desire problems were associated with psychological problems, relationship problems, and drug use, which make it more complex for GPs to treat these sexual dysfunctions by themselves. The loss of sexual drive may be partially a normal adaptation to stress. A less satisfactory relationship does not 
always need a medical solution (Bancroft, 2002). When loss of sexual desire is a side effect of drug use, the GP may assist in revealing and solving the problem. Certainly, the extent to which the side effects of several drugs and comorbidity like diabetes mellitus adversely influence sexual desire is underestimated (Trigwell, 1999). This subject needs more attention in general practice.

Sexual arousal problems in men (mainly erection problems in this study) were less often referred after one consultation compared with other sexual dysfunctions, and in most cases, medication was prescribed by the GP. So men with erection problems mainly seem to visit their GP to obtain a prescription for PDE-5 inhibitors (or a GP is inclined to prescribe PDE-5 inhibitors when confronted with this problem). These findings are consistent with another Dutch study, where in 59\% of cases, medication was prescribed for erection problems (Vliet Vlieland et al., 2002).

The results of our study indicate that women hardly consult their GP concerning orgasm problems. Kedde and De Haas (2006) concluded that $10 \%$ of women in The Netherlands experience an orgasmic dysfunction. Considering this percentage, one would expect that GPs see women with orgasm problems in their practice more often than appears to be the case. Similarly, low percentages are found in the sexological outpatient clinics in The Netherlands (Kruijer \& Kedde, 2010), where only $2 \%$ of the women who started treatment in 2009 were diagnosed with an orgasm problem. Moreover, orgasm problems are not even registered as comorbid dysfunctions, for example in combination with sexual desire problems and sexual arousal problems. Apparently, women with orgasmic dysfunction do not tend to seek help. Maybe women are more likely to seek help for those sexual problems that may also be experienced as problematic by their male partners, such as dyspareunia and hypoactive sexual desire, as these two problems interfere with pleasurable sex for both partners.

Also, our study showed that GPs physically examine women more frequently than they examine men. This is not surprising because from literature, it is known that a physical examination does not contribute much to the diagnosis of erectile dysfunction except for reassurance for the patient (Leusink et al., 2008). In addition, men may in many cases request a drug prescription from their GP and may not be interested in a physical examination. Moreover, the fact that physical examinations are more frequently performed in female patients is certainly a reflection of professional guidelines regarding women with pain symptoms during sexual intercourse (Van Lankveld, Ter Kuile, \& Leusink, 2010). Although nearly all patients had a partner, in most cases, spouses were not present during these consultations. This indicates that people mainly contact their GP individually concerning sexual dysfunctions, although this does not mean that the spouse is not important when further help is needed. As Fitter et al. (2009) already concluded, the context and relationship of patients are important elements to include in the treatment or therapy.

\section{Strengths and Limitations of the Study}

Our study presents unique data about the involvement of Dutch GPs in treating sexual function problems in their patients. Nowadays, it is generally acknowledged that GPs should be capable of treating most single sexual function problems themselves (Van Duin, Nijholt, \& Maiburg, 2009). The number of follow-up consultations in our study also points in this direction. Considering the higher referral rate for women, mainly to secondary care services, it appears that GPs often decide that more expertise is needed to treat sexual dysfunction in women. In our study, these women were often referred to a gynecologist, which is adequate. But it may be preferable to refer women with sexual pain problems to a gynecologist-sexologist. Officially registered sexologists in The Netherlands are better skilled than gynecologists to take a sexual case history and assess sexual problems within a biological, psychological, and sociological framework. In that sense, informing GPs about adequate referral possibilities may be advisable.

Nowadays, patients are well informed through the Internet, and anticipated solutions for problems clearly influence consultation behavior. The incidence of consultations for sexual dysfunction where no drugs were prescribed may, however, have been underestimated. Medical records reflect only a part of the interaction between doctor and patient and are a condensed version of the truth. Confidential issues including sexual problems may be considered to be sensitive information and are not always recorded by GPs, especially when no drugs have been prescribed and when the patient was not referred. In addition, the daily routine of clinical practice tends to underreport issues that create extra work such as having to complete questionnaires. On the other hand, with chronic diseases such as diabetes mellitus, hypertension, and cardiovascular disease, GPs may consider it routine to ask about sexual problems when occurrence of such problems may be anticipated by the disease itself and/or the prescribed medication. These questions may then be recorded under the disease causing the problem and not coded separately, so that the problem 
cannot be identified from the GP's medical records as a sexual problem. Therefore, it is our hypothesis that GPs in our study tends to underestimate their involvement in this area. International literature shows a higher GP consultation rate for sexual dysfunction in women than in men (Nazareth et al., 200), and such differences by country may be a result of cultural differences in addition to gender aspects, differences in study design, differences in the organization of health care services with regard to drug prescription, and insurance issues including possible reimbursement of drugs.

\section{CONCLUSION}

During the period from 2003 to 2008, the help-seeking pattern of men and women consulting their GP for a sexual dysfunction appeared to be stable. The association of several sexual dysfunctions with psychological, physical, and relationship problems and with drug prescription in our study shows that GPs are often dealing with complex multifactorial dynamics and therefore have an important role in revealing contributing factors when counseling the patient. Co-occurrence of sexual dysfunction among women probably resulted in a higher referral rate to secondary care services. Apparently, a gender-sensitive approach, an open mind to differences in sexuality, and excellent communication skills are needed for successful counseling and treatment of sexual problems. Besides these aspects, GP training and postgraduate training should focus on a multidisciplinary approach when dealing with women and men with sexual dysfunction. Therefore, enhancing competence in counseling sexual dysfunction, especially in relation to comorbidity such as chronic conditions like diabetes mellitus, cardiovascular diseases, and psychological and relationship problems, is needed.

\section{Acknowledgments}

This study was funded by the Dutch Ministry of Health, Welfare, and Sport. We would like to thank all general practitioners of the Dutch Sentinel General Practice Network for their participation in the study. We thank Mrs. M. Heshusius-Valen for a crucial role in the data collection process.

\section{REFERENCES}

1. Bancroft, J. 2002. The medicalization of female sexual dysfunction: The need for caution. Archives of Sexual Behavior, 31: 451-455.

2. Courtney, M. 1976. Presentation of sexual problems in general practice. British Journal of Family Planning, 2: 38-39.

3. Donker, G. 2009. Continue Morbiditeits Registratie Peilstations Nederland 2008 [The Dutch Continuous Morbidity Registration Sentinel Stations], Utrecht, The Netherlands: NIVEL.

4. Fitter, J., Hayter, M. and Wylie, K. 2009. What factors influence individuals and couples to seek help for sexual and/or relationship difficulties from primary care pro- fessionals? An exploratory qualitative study. Sexual and Relationship Therapy, 24: 333-346. [Taylor \& Francis Online]

5. Golombok, S., Rust, J. and Pickard, C. 1984. Sexual problems encountered in general practice. British Journal of Sexual Medicine, 11: 171-175.

6. Kedde, H. and De Haas, S. 2006. "Problemen met het seksueel functioneren [Sexual functioning problems]". In Seksuele gezondheid in Nederland 2006 [Sexual health in the Netherlands 2006], Edited by: Bakker, F. and Vanwesenbeeck, I. 123-137. Delft, , The Netherlands: Eburon.

7. Kolthof, E. 2004. Taakopvatting psychosociale zorgverlening versmald. Huisarts en Wetenschap, 47: 441

8. Kruijer, H. and Kedde, H. 2010. LOPS registratie 2009 [Registration of sexological outpatient clinics in the Netherlands 2009], Utrecht, The Netherlands: Landelijk Overleg van Poliklinieken Seksuologie, Rutgers Nisso Groep.

9. Leusink, P., De Boer, L. J., Vliet Vlieland, C. W., Rambharose, V. R., Sprengers, A. M., Mogendorff, S. W. and Van Rijn-Van Kortenhof, N. M. M. 2008. NHG-Standaard Erectiele disfunctie [GP treatment guideline for erectile dysfunction]. Huisarts \& Wetenschap, 51: 381-394.

10. Lewis, R. W., Fugl-Meyer, K. S., Corona, G., Hayes, R. D., Laumann, E. O., Moreira, E. Jr. and ... Segraves, T. 2010. Definitions/epidemiology/risk factors for sexual dysfunction. Journal of Sexual Medicine, 7: 1598-1607.

11. Marwick, C. 1999. Survey says patients expect little physician help on sex. Journal of the American Medical Association, 281(23): 2173-2174.

12. National Platform for Outpatient Clinics in Sexology. 1998. Codering seksuele problemen [Classification of sexual problems], Utrecht, The Netherlands: Author. 
Kedde, H., Donker, G., Leusink, P., Kruijer, H. The incidence of sexual dysfunction in patients attending Dpitch general practitioners. International Journal of Sexual Health: 2011, 23(4), 269-277

13. Nazareth, I., Boynton, P. and King, M. 2003. Problems with sexual dysfunction in people attending London general practitioners: Cross-sectional study. British Medical Journal, 327: 1-6.

14. Read, S., King, M. and Watson, J. 1997. Sexual dysfunction in primary medical care: Prevalence, characteristics, and detection by the general practitioner. Journal of Public Health, 19: 387-391.

15. Simons, J. S. and Carey, M. P. 2001. Prevalence of sexual dysfunctions: Results from a decade of research. Archives of Sexual Behavior, 30: 177-219.

16. Spence, S. 1992. Problems that patients feel are appropriate to discuss with their GPs. Journal of Social Medicine, 85: 669-673.

17. Trigwell, P. 1999. Sexual dysfunction in women with diabetes mellitus: Addressing impaired arousal. Sexual and Marital Therapy, 14: 385-397.

18. Van Duin, B. J., Nijholt, A. J. and Maiburg, H. J. S. 2009. Competentieprofiel en eindtermen van de huisarts. Utrecht, The Netherlands: Concilium voor de Huisartsopleiding.

19. Van Lankveld, J., Ter Kuile, M. and Leusink, P. 2010. Seksuele disfuncties, [Sexual dysfunction. Diagnostics and treatment]. Diagnostiek en behandeling. Houten, The Netherlands: Bohn Stafleu Van Loghum.

20. Vliet Vlieland, C., Eekhof, J., Schuil, S., Maris, C., de Bock, T, Ong, R. and Springer, C. 2002. Erectiele disfunctie in de huisartsenpraktijk: Veranderingen in incidentie en in beleid van de huisarts sinds de introductie van sildenafil [Erectile dysfunction in general practice: Changes in incidence and policy after the introduction of sildenafil]. Tijdschrift voor Seksuologie, 26: 239-244.

21. Whipple, B., Knowles, J. and Davis, J. 2007. "Health benefits of sexual expression". In Sexual health: Vol. 1. Psychological foundations, Edited by: Tepper, M. and Owens, A. 17-28. Westport, CT: Praeger.

\section{[TABLES]}

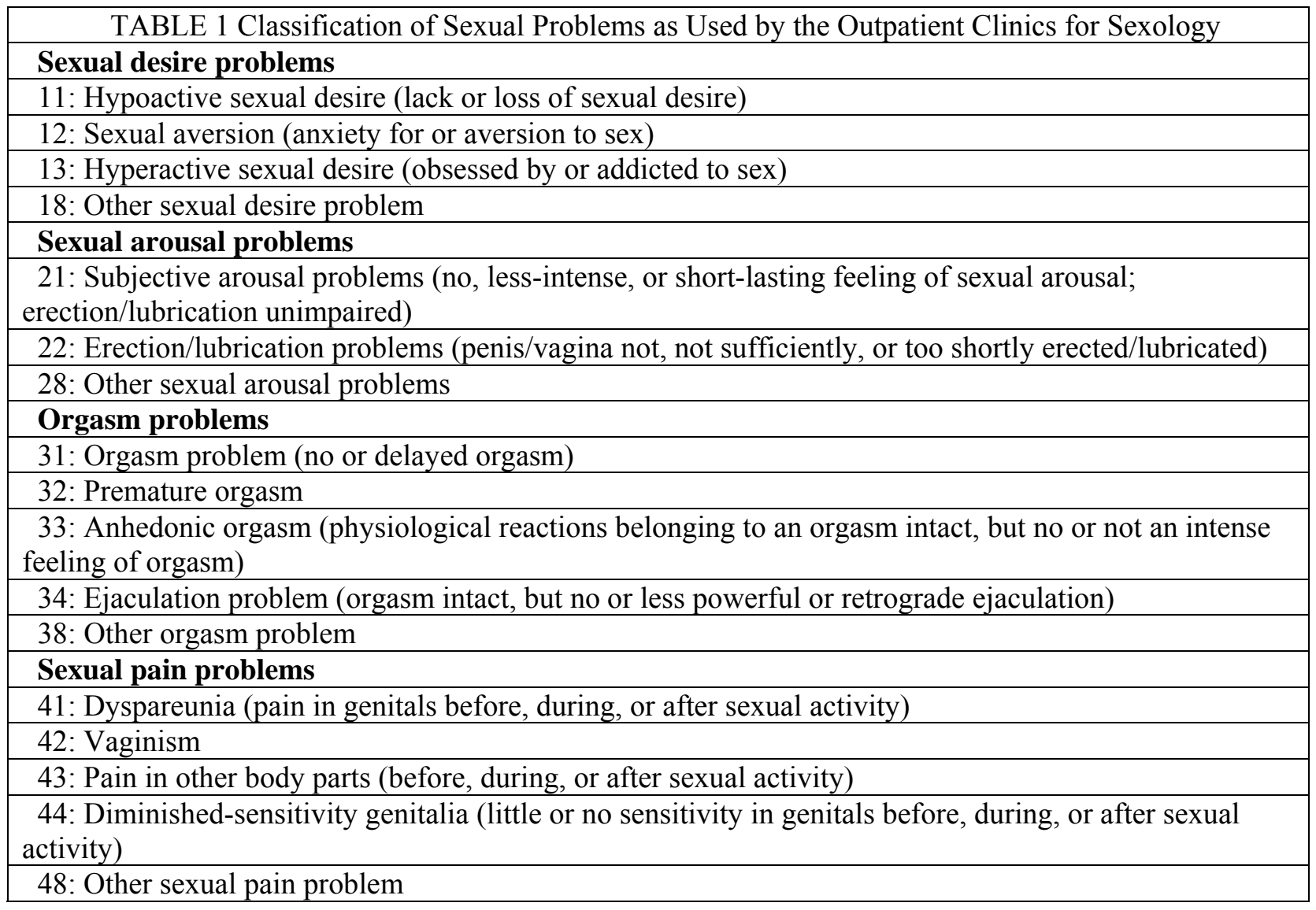


Kedde, H., Donker, G., Leusink, P., Kruijer, H. The incidence of sexual dysfunction in patients attending Dpitch general practitioners. International Journal of Sexual Health: 2011, 23(4), 269-277

TABLE 2 Incidence of Patients Consulting a GP for Sexual Function Problems per 100,000 Patients During 2003-2008

\begin{tabular}{|l|c|c|c|}
\hline & Male (n = 492) & Female (n = 234) & Total (n = 726) \\
\hline Sexual desire problems & & & 9.7 \\
\hline Hypoactive sexual desire & 5.9 & 13.3 & 1.2 \\
\hline Sexual aversion & 0.5 & 2.0 & 1.1 \\
\hline Hyperactive sexual desire & 2.0 & 0.3 & 0.5 \\
\hline Other sexual desire problem & 0.3 & 0.7 & 7.0 \\
\hline Sexual arousal problems & & & 49.5 \\
\hline Subjective arousal problems & 10.4 & 3.7 & 0.5 \\
\hline Erection/lubrication problems & 95.6 & 4.4 & \\
\hline Other sexual arousal problems & 1.0 & 0.0 & 1.7 \\
\hline Orgasm problems & & & 3.3 \\
\hline Orgasm problem & 1.8 & 1.7 & 0.3 \\
\hline Premature orgasm & 6.8 & 0.0 & 1.6 \\
\hline Anhedonic orgasm & 0.3 & 0.3 & 0.6 \\
\hline Ejaculation problem & 3.1 & 0.3 & 15.2 \\
\hline Other orgasm problem & 1.3 & 0.0 & 1.5 \\
\hline Sexual pain problems & & & 0.6 \\
\hline Dyspareunia & 1.3 & 28.5 & 0.5 \\
\hline Vaginism & 0.0 & 2.9 & 0.6 \\
\hline Pain in other body parts & 0.2 & 1.0 & 95.4 \\
\hline Diminished-sensitivity genitalia & 0.2 & 0.7 & \\
\hline Other sexual pain problem & 1.0 & 0.2 & \\
\hline Total & 131.6 & 59.8 & \\
\hline
\end{tabular}


Kedde, H., Donker, G., Leusink, P., Kruijer, H. The incidence of sexual dysfunction in patients attending Dpitch general practitioners. International Journal of Sexual Health: 2011, 23(4), 269-277

\begin{tabular}{|c|c|c|c|c|c|c|c|c|c|}
\hline 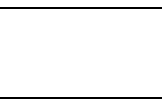 & $\begin{array}{l}\text { Psychological } \\
\text { problems }\end{array}$ & $\varnothing$ & $\begin{array}{l}\text { Relationship } \\
\text { problems }\end{array}$ & $\varnothing$ & $\begin{array}{r}\text { Physical } \\
\text { problems }\end{array}$ & $\varnothing$ & $\begin{array}{l}\text { Medicine } \\
\text { use }\end{array}$ & $\varnothing$ & Opera \\
\hline \multicolumn{10}{|l|}{ Men } \\
\hline $\begin{array}{l}\text { Sexual } \\
\text { desire } \\
\text { problems }\end{array}$ & 40.6 & $.14 * *$ & 31.0 & $.16^{* *}$ & 12.9 & ns & 24.1 & ns & 0.0 \\
\hline $\begin{array}{l}\text { Sexual } \\
\text { arousal } \\
\text { problems }\end{array}$ & 19.4 & ns & 10.3 & ns & 24,0 & ns & 26.9 & ns & 5.1 \\
\hline $\begin{array}{r}\text { Orgasm } \\
\text { problems }\end{array}$ & 16.7 & ns & 6.3 & ns & 10.6 & ns & 15.2 & ns & 6.4 \\
\hline $\begin{array}{l}\text { Sexual } \\
\text { pain } \\
\text { problems }\end{array}$ & 0.0 & ns & 20.0 & ns & 20.0 & ns & 0.0 & ns & 20.0 \\
\hline $\begin{array}{l}\text { Total } \\
\text { men }\end{array}$ & 20.1 & & 11.4 & & 21.8 & & 25,0 & & 5.3 \\
\hline \multicolumn{10}{|l|}{ Women } \\
\hline $\begin{array}{l}\text { Sexual } \\
\text { desire } \\
\text { problems }\end{array}$ & 30.5 & $.16^{*}$ & 20.3 & ns & 8.5 & $-.18^{*}$ & 32.2 & $.34 * * *$ & 1.8 \\
\hline $\begin{array}{l}\text { Sexual } \\
\text { arousal } \\
\text { problems }\end{array}$ & 27.3 & $\mathrm{~ns}$ & 16.1 & ns & 16.1 & ns & 9.7 & $.13^{* *}$ & 0.0 \\
\hline $\begin{array}{r}\text { Orgasm } \\
\text { problems }\end{array}$ & 12.5 & ns & 12.5 & ns & 0.0 & ns & 11.1 & ns & 12.5 \\
\hline $\begin{array}{l}\text { Sexual } \\
\text { pain } \\
\text { problems }\end{array}$ & 13.7 & $*^{-.18 *}$ & 11.2 & ns & 28.5 & $.23 * *$ & 5.3 & $\begin{array}{l}-.26^{*} \\
* *\end{array}$ & 8.6 \\
\hline $\begin{array}{c}\text { Total } \\
\text { women }\end{array}$ & 20.3 & & 14.5 & & 20.4 & & 13.6 & & 5.7 \\
\hline
\end{tabular}


Kedde, H., Donker, G., Leusink, P., Kruijer, H. The incidence of sexual dysfunction in patients attending Dpitch general practitioners. International Journal of Sexual Health: 2011, 23(4), 269-277

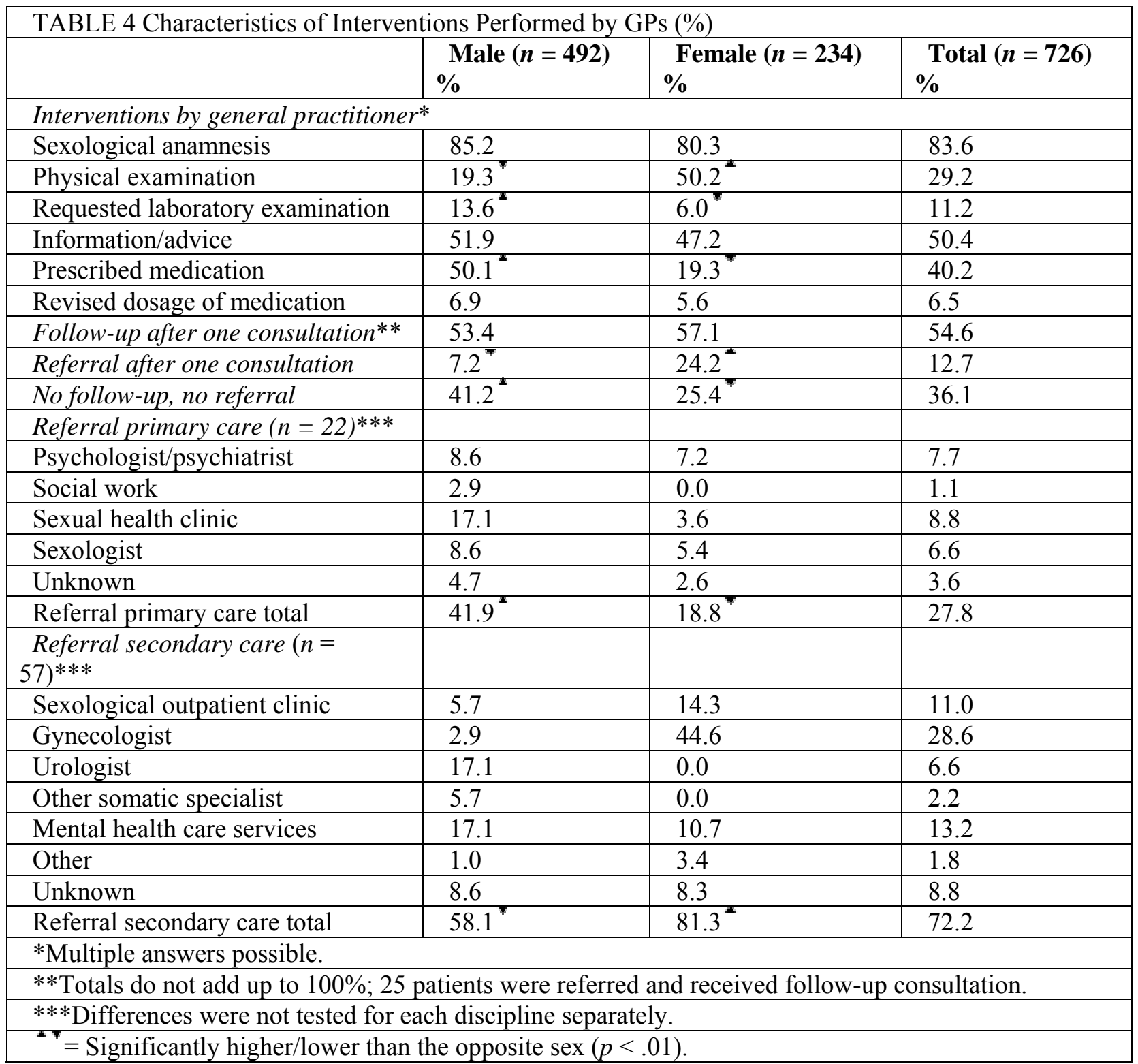

